Article

\title{
Exploring the Systematic Attributes Influencing Gerontechnology Adoption for Elderly Users Using a Meta-Analysis
}

\author{
Jining Zhou ${ }^{1,2,3}$, Bo Zhang ${ }^{3,4}$, Runhua Tan ${ }^{3}$, Ming-Lang Tseng ${ }^{5,6,7, * \mathbb{D} \text { and Yaya Zhang }}{ }^{8}$ \\ 1 School of Economics and Management, Hebei University of Technology, Tianjin 300401, China; \\ 201611701010@stu.hebut.edu.cn \\ 2 School of Chinese and Broadcasting, Hengshui University, Hengshui 053000, China \\ 3 National Engineering Research Center for Technological Innovation Method and Tool, Hebei University of \\ Technology, Tianjin 300401, China; zhbotute@163.com (B.Z.); rhtan@hebut.edu.cn (R.T.) \\ 4 School of Economics and Management, Tianjin University of Technology and Education, \\ Tianjin 300222, China \\ 5 Institute of Innovation and Circular Economy, Asia University, Taichung 41354, Taiwan \\ 6 Department of Medical Research, China Medical University, Taichung 40402, Taiwan \\ 7 Faculty of Economics and Management, University Kebangsaan Malaysia, \\ Bandar Baru Bangi 43600, Malaysia \\ 8 Office of Taocheng District People's Government, Hengshui 053000, China; AD_JOEY@Outlook.com \\ * Correspondence: tsengminglang@gmail.com or tsengminglang@asia.edu.tw
}

Received: 8 March 2020; Accepted: 30 March 2020; Published: 3 April 2020

check for updates

\begin{abstract}
This study aims to explore the key systematic attributes influencing the acceptance of gerontechnology by seniors in response to global aging and rapid technological progress. A meta-analysis was carried out to quantitatively synthesize the results of 25 empirical studies published from 2010 to 2020 . After standardized coding and descriptive statistics, as well as tests and analysis of main effects and heterogeneity, publication bias. The following results were obtained: Perceived usefulness and perceived ease of use have a significant positive impact on the user's attitude and behavioral intention; performance expectancy, effort expectancy, trust, technical performance and subjective norm have a significant positive correlation with the user's behavioral intention; social influence, facilitating conditions have a positive correlation with the user's behavioral intention; anxiety has a significant negative correlation to the user's behavioral intention. The key systematic influencing attributes are classified into three categories: (1) User individual characteristics; (2) product and technical characteristics; and (3) environmental characteristics. This study provides researchers and practitioners with a systematic evidence-based basis to reduce the gap in decision-making for gerontechnology practices.
\end{abstract}

Keywords: health care; elderly; gerontechnology; acceptability; meta-analysis

\section{Introduction}

The global aging of the population and the rapid advances in technology have promoted the development of gerontechnology, which technology helps the seniors to be more independent, healthy and safe in their later life [1]. Gerontechnology has been proved by a number of studies that it has great help for the seniors in independent living, social activity, and health care-and it is an important technical means to realize ageing in place [2-4]. 5G technology, internet of things technology, and artificial intelligence technology have developed rapidly. The advantages of low cost and convenience 
of gerontechnology are increasingly apparent and gradually become an important way to solve insufficient resources and cope with the problem of aging [3].

The emergence of this technology is to solve the problems and difficulties caused by aging, such as supporting the independent living and social activities of the elderly [5]; prolonging the working age of the elderly and reducing the medical expenses of the elderly in the later years [1]; and ensure the health, comfort and safety of the elderly [6]. During the technology development, there are significant differences in the definition and understanding of elderly care needs by users and technicians, which has seriously affected the development and promotion of assistive technology [7]. Prior studies have attended the attitude, intention and satisfaction of the elderly to adopt gerontechnology to explain the influencing systematic attributes of the user acceptance of a certain technology [8-10]. However, the conclusions obtained by many studies have some differences, or even completely opposite. In order to explore the influencing attributes that affect the user's acceptance of gerontechnology with an objective attitude and a comprehensive perspective. A meta-analysis of 25 empirical studies published between 2010 and 2020 was conducted in this study.

The meta-analysis is a statistical analysis method that synthesizes the results of multiple experiments or quasi-experiments and obtains the average experimental effect value [11]. It is an exploratory analysis compared with narrative literature reviews by integrating the effect amount into the analysis and then obtaining inferred results $[12,13]$. Prior studies have noticed the important value of the meta-analysis method in the field of health care studies. Zhao et al. [14] conducted a meta-analysis on the influencing systematic attributes of mobile medical service adoption, but the target sample was all-age users. Hauk et al. [15] conducted a meta-analysis with aging users as the study sample in understanding between age and technology acceptance for influencing systematic attributes. Based on previous studies, this study takes the elderly as the research sample and analyzes the attributes that affect the adoption of gerontechnology from a comprehensive perspective.

In addition, this study is to achieve scientific analysis and uses the co-occurrence analysis function of CiteSpace 5.5 to obtain a list of hot words in the gerontechnology field. The search terms in the field of gerontechnology adoption were expanded to ensure the completeness of the retrieved data; In the analysis part, CMA 3.0 (Comprehensive Meta-Analysis 3.0) software was used to process and analyze the data, ensuring the valid analysis; in the process of hypothesis proposal and discussion, relying on the human, machine, and environment three-element composition theory in ergonomics [16]. NVivo12 software was used to efficiently encode the data, and classified the influencing systematic attributes.

Gerontechnology's low-cost and convenient advantage are becoming increasingly apparent as the world's population ages amid this information era [3]. A large number of research results show that the elderly tend to aging-in-place [2-4], gerontechnology will play an increasingly important role in improving the quality of life for the elderly $[5,6]$. Moreover, the proportion of the elderly who continue to stay at work or return to work will increase with the extension of a healthy lifetime; which will further enlarge the elderly's demand for gerontechnology [1,7]. The objectives of this study lie in the influencing systematic attributes of the elderly's gerontechnology adoption and the proposal of the overall framework of the influencing systematic attributes. Showing government administrators, academicians and related stakeholders a systematic evidence-based basis to reduce the gap between decision-making and practice.

1. To analyses the theoretical basis for an empirical study on technology adoption for the elderly;

2. To find the key influencing systematic attributes considered by the elderly when adopting the gerontechnology;

3. To classify ergonomics in three categories of influencing systematic attributes such as user individual characteristics; product and technical characteristics; and environmental characteristics.

The rest of this study is organized as follows. Section 2 puts forward the hypothesis of this study through the analysis of Prior study based on the adoption of relevant theories and reference to ergonomics; Section 3 shows the analytical process of this study through the three stages of 
literature acquisition, data coding, and data analysis; Section 4 tests and analyses of main effects and heterogeneity, publication bias on the data. Section 5 explains the theoretical significance and management implications. Section 6 summarizes the full text, and describes the lack of and future study.

\section{Proposed Model}

Prior studies conducted on the behavior of gerontechnology acceptance study. Through the analysis of a large number of documents, the theoretical basis of the study lies in the theory of reasoned action, the theory of planned behavior, and the technology acceptance model (TAM) and unified theory of acceptance and use of technology (UTAUT) evolved on this basis. The theoretical models are based on the adopted theories to increase constructs or combine with other theories, including the elderly smart home technology acceptance model [17]; the conceptual extension model based on UTAUT model [18,19]. Pal et al. [20] presented the effectiveness of three theoretical models of TAM, rational behavior theory, and planned behavior theory on the adoption of smart homes by the elderly. This study uses the structural equation model to analyze the influencing systematic attributes of adoption.

Ergonomics has been widely used in various fields, especially mobile devices and smart furniture, which are in direct contact with the human body. Ergonomics refers to the three elements of human, machine, and environment as the main body of a human-machine system, making the design of the machine and the living environment suitable for the physiological and psychological characteristics of the human, so that people can work and live in comfortable and convenient conditions [16]. Prior studies based on the models to explain the systematic attributes that influence the acceptance behavior of elderly users [17]. In lieu of those studies, the empirical study results provide rich data for Meta quantitative analysis. The acceptance behavior of gerontechnology users is the human-computer interaction behavior of users and technology in order to derive universal user behavior analysis conclusion. This study analyzes the influencing systematic attributes of the user acceptance behavior from three dimensions based on human ergonomics (user individual characteristics; product technical characteristics; environmental characteristics).

\subsection{User Individual Characteristics}

The user-perceived gerontechnology is an innovation in the form of products and services based on network technology, and the user's level of understanding and cognition is low. These differences have a significant impact on the acceptance of gerontechnology. In the field of gerontechnology adoption, the influencing systematic attributes of the individual characteristics are summarized as physical, psychological, economic conditions, knowledge and experience.

Physiological attributes include gender, age, and health condition. Pan and Jordan [21] compared the data between internet users and non-users based on the extended TAM, with a sample of 374 Chinese people over the age of 58 . He found that older people who currently use the internet tend to be male and younger, suggesting that gender and age have important regulatory roles in such decision-making processes. Psychological influencing systematic attributes include behavioral attitudes, technological fear, mastery of health knowledge and demand for health. Based on the UTAUT model, Hoque and Sorwar [22] collected data from nearly 300 participants aged 60 and over in Bangladesh and found that technical anxiety has a significant negative impact on the behavior intention of adopting health by the elderly. This study result provided high-value suggestions for the promotion of related technologies in developing countries. Economic status refers to the income of users.

Pal et al. [17] indicated the Elderly Smart Home Technology Acceptance Model, analyzed the behavioral data of 254 elderly people using smart homes technology, and found a significant relationship between affordability and behavioral intention. Knowledge and experience include the user's education level, and Prior experience in using gerontechnology products or services. Mitzner et al. [23] analyzed the archival data of 150 elderly people (65-98 years old) of different races and found that early computer experience has a significant impact on the TAM adoption of 'personal reminder information' and 
'social management'. Prior studies are suggested that computer experience promotes the adoption of related technology products. The following hypotheses are proposed for meta-analysis.

Hypothesis 1 (H1). Affordability (AF) has a positive impact on behavior intention.

Hypothesis 2 (H2). Technology (TE) experience has a positive impact on usage acceptance.

Hypothesis 3 (H3). Anxiety (AI) has a negative impact on behavior intention.

\subsection{Product Technical Characteristics}

The advantages of low cost and convenience of gerontechnology are increasingly apparent under the background of population aging and information era. Gerontechnology makes easier to provide the elderly with various resources needed for life and medical treatment compared with the traditional elderly care method. If users realize the advantages of gerontechnology and promote the acceptance and long-term use of related technologies. The influencing systematic attributes of the technology and product characteristics are summarized as three aspects: the benefits and value gained from use; the ease of learning and operation; and the comprehensive quality of products and services.

Benefits and values are expectations of the benefits that can be derived from the use of technology. The more support, the closer to expectations, the stronger the willingness to use [24,25]. It also includes the health conditions that can be improved during adoption and use [26]. Moreover, the social gratification that can be achieved to reduce loneliness and enhance communication with friends [27]. The degree of difficulty of learning and operation includes the degree of difficulty that older users think they can complete the work themselves. The easier it is to learn and operate, the more they are willing to use it [24].

Prior studies based on TAM have paid attention to the impact of PU and PEOU on gerontechnology adoption. Pan and Jordan [21] conducted an empirical study on the internet usage behavior of the elderly, and proposed that perceived usefulness, perceived ease of use are important predictive indicators for the internet adoption of the elderly. Based on the study results, an Extension TAM was constructed. Subsequently, Syed-Abdul et al. [24] investigated the user attitude of elderly to adopt virtual reality technology-based on TAM model. Perceived Usefulness, Perceived Ease of Use, social norms, and Perceived joy have a significant impact on the intent to use virtual reality. It is suggested that the seniors are welcome regarding the usefulness, ease of use, and enjoyable experience of new technologies. The following hypotheses are proposed for meta-analysis.

Hypothesis 4 (H4). Perceived usefulness (PU) has a positive impact on behavior attitude.

Hypothesis 5 (H5). Perceived Ease of Use (PEOU) has a positive impact on behavior attitude.

Hypothesis 6 (H6). Perceived usefulness (PU) has a positive impact on behavior intention.

Hypothesis 7 (H7). Perceived Ease of Use (PEOU) has a positive impact on behavior intention.

In addition, the UTAUT model applied measured the effect of expected performance, effort expectation, and trust on the gerontechnology adoption behavior of the elderly. Quaosar et al. [25] conducted a questionnaire survey on mobile technology as the study object about the user elderly people behaviors based on the Extended Technology of Integrated Technology. The study found that performance expectations, effort expectations, social influence, and trust have significant effects on the intention of older people to use mobile medical services. Chu et al. [28] found that perceived trust has a significant impact on enhancing older adults' acceptance of robots through mixed methods study. The hypotheses are proposed as follows.

Hypothesis 8 (H8). Performance Expectancy (PE) has a positive impact on behavior intention.

Hypothesis 9 (H9). Effort Expectancy (EE) has a positive impact on behavior intention.

Hypothesis 10 (H10). Trust (TR) from the products or service has a positive impact on behavior intention. 
The comprehensive quality of products and services includes two aspects that users expect: Technical performance and facilitating conditions. Technical performance includes the compatibility of gerontechnology products and services with the use environment [29], the reliability of output quality and safety during use [30]. The impact of technical performance on adoption behavior, such as Talukder et al. [30] conducted an empirical study on the adoption behavior of Wearable healthcare technology (WHT) for 325 seniors over 65. The study found that functional consistency, self-actualization and hedonistic motivation has a positive relationship with WHT adoption. Facilitating conditions mean that elderly users expect to get help from the surrounding environment in the process of adopting and using gerontechnology [31,32]. Different from the recommendations and influences in the characteristics of the social environment, this help is reflected in technical assistance in operation and maintenance. Users inevitably encounter difficulties in the use of new technologies, and the elderly cannot solve these difficulties independently [31]. In the process of adoption, the seniors are bound to expect that in the future to get help from nearby resources. The hypotheses are proposed for meta-analysis:

Hypothesis 11 (H11). Technical performance (TP) has a positive impact on behavior intention.

Hypothesis 12 (H12). Facilitating conditions $(F C)$ has a positive impact on behavior intention.

\subsection{Environmental Characteristics}

The elderly are affected by the gradual degradation of physiological functions and aging. Compared with young people, the elderly are more likely to be affected by family, friends and institutions. Based on the analysis of Prior study results in the field of gerontechnology adoption, the influencing systematic attributes of the Environmental characteristics are summarized as the impact of recommendations from friends or institutions around the elderly [21,24]. The theoretical basis for the measurement of these influencing systematic attributes is the theory of reasoned action [33], and the theory of planned behavior [34]. The constructs in these theoretical models are 'social influence' and 'subjective norm'. Since the two constructs are basically the same in the formulation of the concepts [21], this study classifies the two as social environment characteristics. The constructs are derived from different adoption models, so this study did not combine the effect values of the two for meta-analysis, but conducted special measurements and discussions.

Prior studies focusing on the environmental characteristic systematic attributes include the impact of approval or recommendation from friends, relatives, community workers, doctors, caregivers, and elderly institutions in the usage of gerontechnology by seniors. Chen et al. [35] developed an adoption model of TV broadband network services for the elderly based on the TAM to gain an empirical understanding of the systematic attributes affecting the use and acceptance of innovative technology service and products. This study conducted a questionnaire survey of 530 elderly people over 50 years old in Taiwan and resulted in social norms, and network externalities have a significant positive impact on users' behavioral intentions. Then, Cajita et al. [36] surveyed 129 elderly people and analyzed the results based on adaptive technology acceptance models. The results show that social influence, perceived ease of use, and perceived usefulness show a significant positive correlation with the intention to use mobile medical technology services. Pan and Jordan [21] obtained similar findings, showing that subjective norms are an important predictor of internet adoption by Chinese seniors. Based on the analysis, the following hypotheses are proposed for meta-analysis:

Hypothesis 13 (H13). Social Influence (SI) has a positive impact on behavior intention.

Hypothesis 14 (H14). Subjective norm (SN) has a positive impact on behavior intention.

A study model on the influencing systematic attributes of gerontechnology adoption behavior is obtained (Figure 1). 


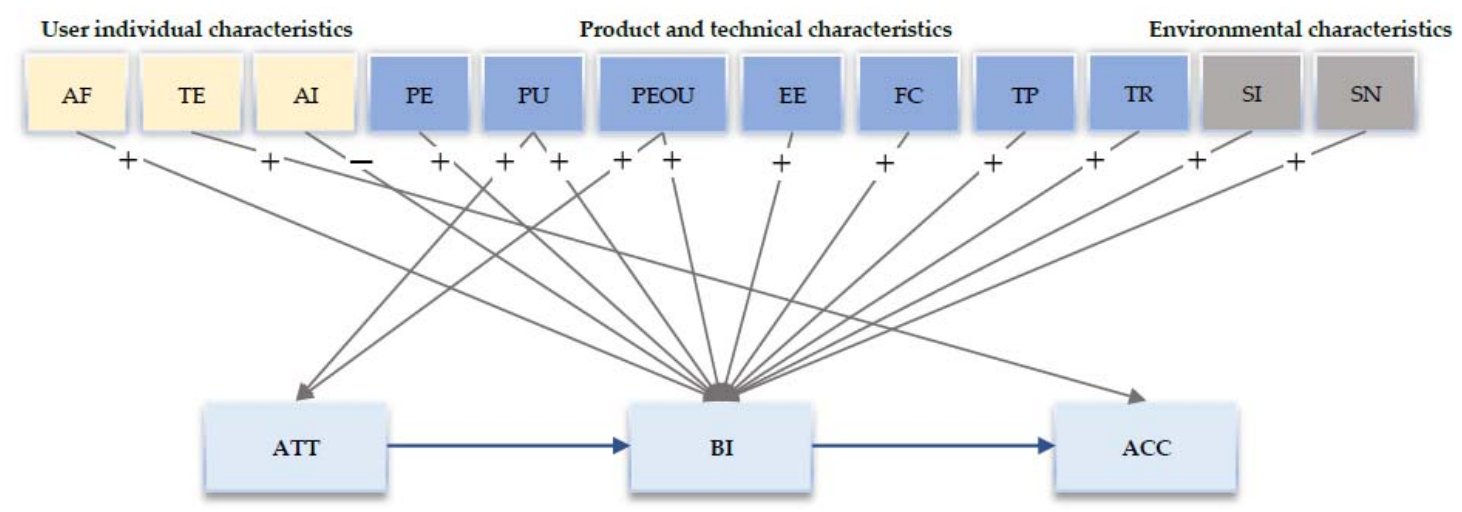

Figure 1. The conceptual model of gerontechnology adoption.

Note: AF-affordability; TE—-technology experience; AI—anxiety; PE-performance expectancy; PU—perceived usefulness; PEOU—perceived ease of use; EE-effort expectancy; FC—facilitating conditions; TP-technical performance; TR-trust; SI-social influence; SN-subjective norm; ATT—attitude; BI—behavioral intention; ACC—acceptance.

\section{Method}

\subsection{Data Collection}

Three sets of compound keywords were searched in the database on January 21, 2020 (Springer, BMJ, SAGE, Highwire, ScienceDirect, ProQuest Medical Library, IEEE Xplore, Web of Science, Google Scholar): (1) "Seniors" and other synonyms; (2) "Adoption", "Acceptance" and other terms related to acceptance theory; (3) "Gerontechnology" and other related terms. Affected by the rapid development of the internet, the Internet of Things, and artificial intelligence technologies, related technologies included in gerontechnology have progressed rapidly, so the search time range for this study was controlled within the past 10 years, from January 2010 to January 2020.

Gerontechnology involves a wide range of technical fields, so CiteSpace 5.5.R2 is used to draw a knowledge map of gerontechnology fields (Figure 2). Keyword co-occurrence analysis was performed on the literature with the theme of "Gerontechnology" to obtain study hotspot technologies in the field. Related parameters: Time slice $=1$, Top $\mathrm{N}=50$, Algorithm $=$ Pathfinder network scaling, Quantity $=$ 130, Timespan $=1906-2020$, other thresholds are system defaults.

In the CiteSpace keyword co-occurrence map, the frequency reflects the number of citations of hot words in the literature data; centrality, which is a quantification of the median value of the pivot keywords, measures the importance of the position of the word in the network. Frequency and centrality can reflect the popularity and importance of keywords in the study area in the knowledge graph map [37]. With reference to the frequency of citations of hot vocabulary and its centrality, the topic search term "gerontechnology" was expanded to obtain a search vocabulary (Table 1).

Table 1. Research term list.

\begin{tabular}{cccccc}
\hline Key Words & Frequency & Centrality & Key Words & Frequency & Centrality \\
\hline gerontechnology & 84 & 0.3 & assistive technology & 2 & 0.01 \\
technology & 20 & 0.17 & telehealth & 2 & 0 \\
information technology & 5 & 0.08 & health care & 2 & 0.01 \\
internet & 4 & 0.06 & system & 2 & 0 \\
smart home & 4 & 0.05 & ehealth & 2 & 0.01 \\
smart hm & 3 & 0.04 & exergame & 2 & 0 \\
model & 3 & 0.04 & robot & 2 & 0 \\
mobility & 2 & 0 & ict & 2 & 0.03 \\
mobile phone & 2 & 0 & e-health & 2 & 0.02 \\
\hline
\end{tabular}




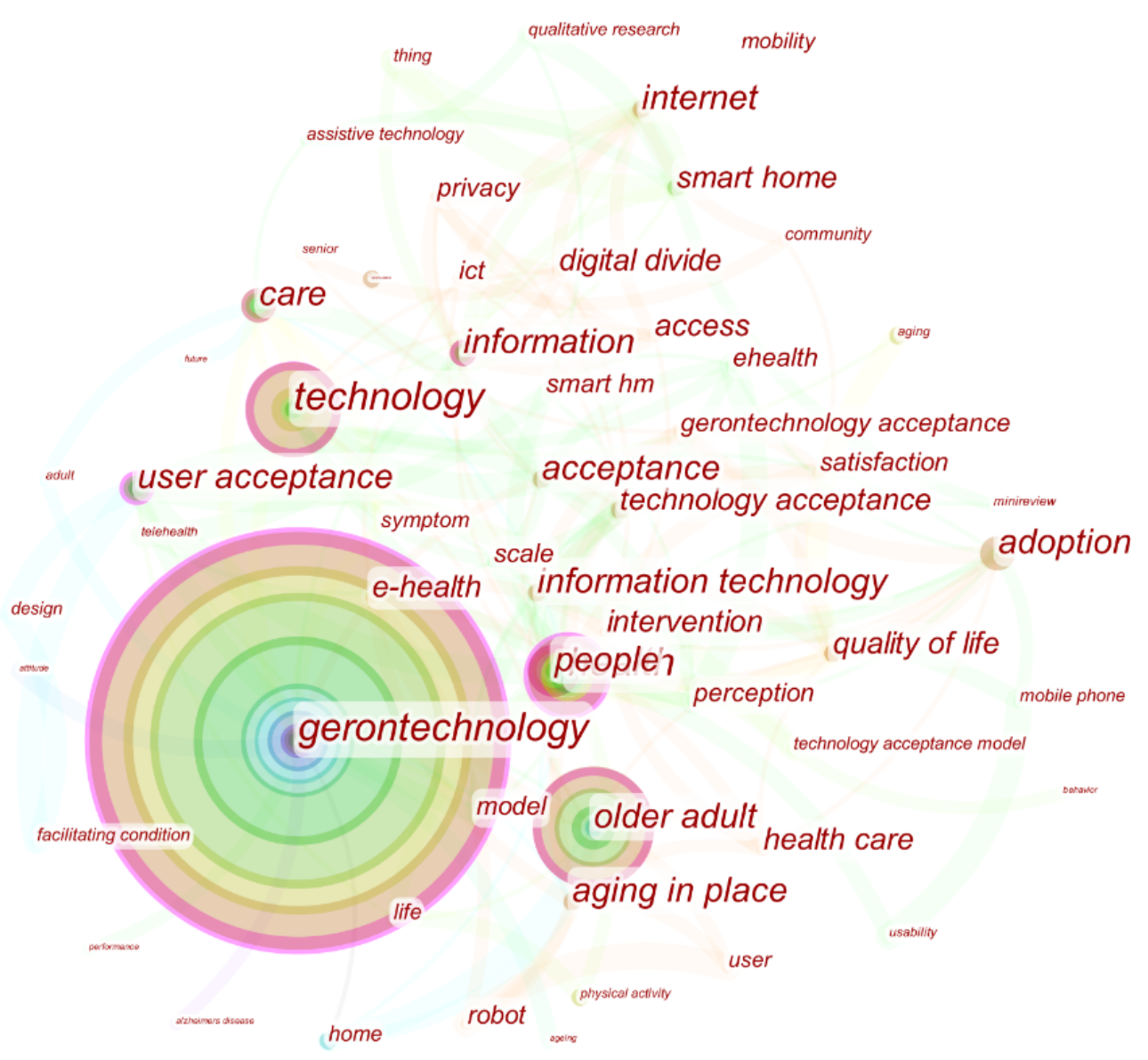

Figure 2. Knowledge map of hotspots in the field of gerontechnology research.

According to the search strategy, 1632 studies were found in the journal library. After removing duplicate results, a total of 1187 studies were identified. Subsequently, the retrieved documents were screened and eliminated according to the following criteria (Table 2).

Table 2. Selection principles.

- The purpose of the study is to analyze the influencing systematic attributes of the adoption of gerontechnology

- The study sample focuses on the elderly population

- Quantitative study

- Data can meet the needs of meta-analysis

This study is completed a comprehensive review of the title, abstract, and full text of the data after six weeks, and finally obtained 25 literature data that met the requirements. The screening process is presented in Figure 3. 


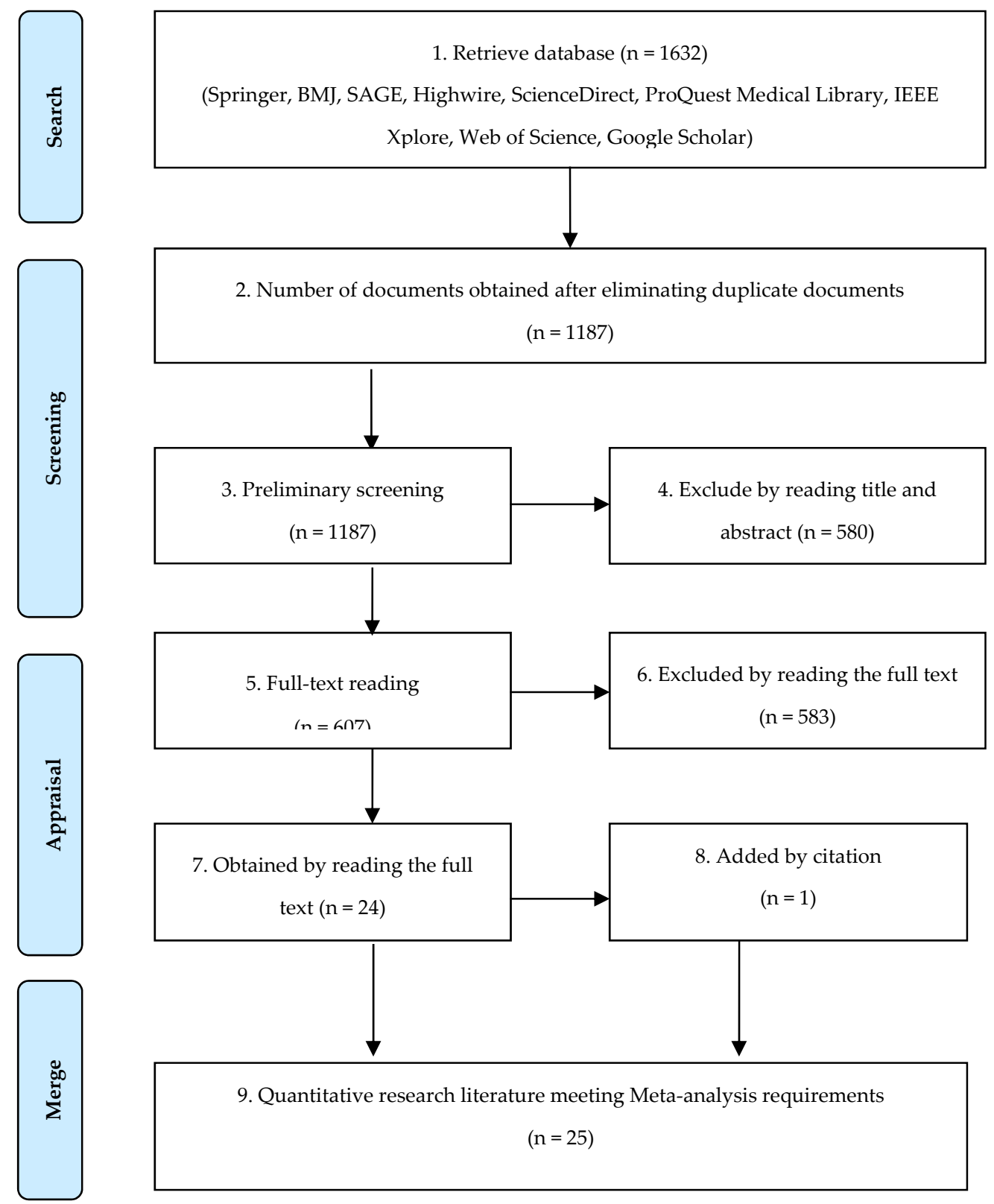

Figure 3. Data collection progress.

\subsection{Data Encoding}

This study is used the Nvivo12 software to cross-encode the data independently to ensure the reliability of the encoding process. This study is to review the inconsistencies. Nvivo12 software is often used for the extraction and analysis of systematic text data, which can implement the encoding and management of multi-sample complex information data. The coding content mainly includes two parts: The description item and effect value statistics item. Descriptive items include basic information, such as title, author, year of publication, and study object. The effect value statistical items include the sample size and statistics that can be converted into effect values, such as the correlation coefficient $r$ value, $t$ value, and $p$ value. For documents that have no correlation coefficient or cannot be converted into correlation coefficients, try to contact the author to obtain the required data.

The coding process follows two main rules: (1) The effect amount is based on the independent sample object as a unit, that is, each independent sample must be completely encoded once. If a hypothetical relationship in the same document provides several correlation coefficients, and these 
correlation coefficients are obtained from different samples, then multiple encodings are required; and (2) in the process of merging variables, if the same variable comes from different documents, the coder needs to read the variable source literature carefully, repeatedly compare the connotations of the variables, and ensure the connotations are exactly same before merging the variables. The analytical group meets to review and resolve when two groups of coding are inconsistent. The information of the 25 independent studies included in the meta-analysis is shown in Table 3.

Table 3. Articles involved in the meta-analysis.

\begin{tabular}{|c|c|c|c|c|}
\hline Author & Sample Size & Object & Country or Area & Year \\
\hline Mei-Liang Chen et al. & 530 & Broadband network & Taiwan & 2011 \\
\hline John S. Burnett et al. & 281 & Communication technology & USA & 2011 \\
\hline Lishan Xue et al. & 700 & Health informatics via a mobile phone & Singapore & 2012 \\
\hline Isabel Maria Macedo & 278 & $\begin{array}{l}\text { Information and communication } \\
\text { technology }\end{array}$ & Portugal & 2017 \\
\hline Shuya Pan et al. & 374 & Internet & China & 2010 \\
\hline Debajyoti Pal et al. & 239 & Internet of things & Thailand et. & 2018 \\
\hline Rakibul Hoque et al. & 274 & M-Health & Bangladesh & 2017 \\
\hline Maan Isabella Cajita et al. & 129 & M-Health & Maryland & 2017 \\
\hline G.M. Azmal Ali Quaosar et al. & 245 & M-Health & Bangladesh & 2018 \\
\hline Mi Sook Lee & 630 & Mobile device & South Korea & 2019 \\
\hline Xitong Guo et al. & 184 & Mobile health services & China & 2011 \\
\hline Leyla Dogruel et al. & 125 & New media & German & 2015 \\
\hline Jiunn-Woei Lian et al. & 574 & Online shopping & Taiwan & 2014 \\
\hline Tracy L. Mitzner et al. & 150 & Personal reminder & USA & 2018 \\
\hline Jing Fan et al. & 14 & Robotic Coach & USA & 2015 \\
\hline Li Chu et al. & 33 & Robots & Taiwan & 2018 \\
\hline Jia Zhou et al. & 351 & Smart phones & China & 2014 \\
\hline DEBAJYOTI PAL et al. & 239 & Smart-home & Thailand et. & 2018 \\
\hline Debajyoti Pal et al. & 239 & Smart-home & Thailand et. & 2018 \\
\hline Miha Cimpermanet et al. & 400 & Telehealth & Slovenia & 2016 \\
\hline Min Zhou et al. & 436 & Telehealth & China & 2019 \\
\hline Van Houwelingen et al. & 256 & Telehealth & Netherlands & 2018 \\
\hline \multirow{4}{*}{ Marcel Heerink et al. } & 40 & The iCat robot & Netherlands & 2010 \\
\hline & 88 & RoboCare robot & Netherlands & 2010 \\
\hline & 30 & The iCat robot & Netherlands & 2010 \\
\hline & 30 & Service robot & Netherlands & 2010 \\
\hline Syed-Abdul et al. & 30 & Virtual reality & Taiwan & 2019 \\
\hline Md. Shamim Talukder et al. & 325 & Wearable healthcare & China & 2020 \\
\hline
\end{tabular}

\subsection{Analysis Procedure}

Meta-analysis is used as the analysis method. The analytical data was processed by CMA 3.0 (Comprehensive Meta-Analysis 3.0) software. Meta-analysis comprehensively evaluates the existing study results by quantitatively merging statistical analysis of multiple independent study results. Due to the scientific nature of its analysis process, the relative universal advantages are obtained [11].

This study is based on the meta-analysis steps Egger et al. [38]. It mainly carried out the steps of determining the study question, searching and selecting the data, extracting the data, checking, and analyzing the results. In the calculation step of the effect value, the correlation coefficient or path coefficient is mainly used as the effect value for analysis. Due to the differences in measurement methods in different studies, correlation coefficients or path coefficients need to be processed into standard effect values in order to perform meta-synthesis analysis. Exclude those results which do not have correlation coefficients or cannot be standardized. In this study, the correlation coefficient $r$ is used as the input effect size, and the Fisher's Z equations are used to calculate the estimated value of $r$. A comparative analysis is performed. The calculation equations of $r$ value are shown as follows:

$$
\begin{gathered}
Z_{i}=0.5 \ln \left(\frac{1+r i}{1-r i}\right) \\
Z=\frac{\sum Z_{i}}{\sqrt{N}}
\end{gathered}
$$




$$
r=\frac{e^{2 \times \text { Fisher's }^{\prime}}-1}{e^{2 \times \text { Fisher's }^{\prime} \mathrm{I}}+1}
$$

The equations for calculating the upper limit and lower limit of the $95 \%$ confidence interval of the effect value $r$ are shown in Equations (4) and (5).

$$
\begin{aligned}
& \text { Upper } \lim i t=r+1.96 \times \text { s.d. } \\
& \text { Lower } \lim i t=r-1.96 \times \text { s.d. }
\end{aligned}
$$

In Equations (1)-(5), s.d is the standard deviation of the path, $r$ is the effect value involved in each path, and $N$ is the sample size.

\section{Data Analysis}

\subsection{Descriptive Statistics}

This section performs a descriptive analysis of the sample data, including hypothetical paths, correlation coefficients, significance and sample size, presented in Table 4. From the number of studies on each path, the number of studies on the path relationship of PU-BI (13 studies) and SI-BI (13 studies) is the largest. Attention also yields relatively more conclusions. It shows that compared with other path hypotheses, these two hypotheses have received more attention and obtained valuable results. After statistical analysis of significance, SI-BI (13 studies) has seven significant and six non-significant, with a significant rate of $53.85 \%$. Similarly, the significant rate of TR-BI (7 studies) is $42.86 \%$ and AF-BI (2 studies) is 50\%. It shows that the research results of these three paths are quite controversial. Analyzing the range of correlations of each path, the difference of PEOU-BI (3.066) is the largest, and the other range of correlations is mainly distributed between 0.2 and 0.6 , which indicates the effects of influencing systematic attributes on user behavior are controversial. In addition, in the display of sample size, the largest sample size was 700, and the smallest sample size was 14 . 
Table 4. Descriptive statistics

\begin{tabular}{|c|c|c|c|c|c|c|c|c|c|c|c|}
\hline \multirow{2}{*}{$\begin{array}{l}\text { Pair-Wise } \\
\text { Relationship }\end{array}$} & \multirow{2}{*}{$\begin{array}{c}\text { Number of } \\
\text { Studies }\end{array}$} & \multicolumn{3}{|c|}{ Range of Correlations } & \multicolumn{3}{|c|}{ Correlations } & \multicolumn{2}{|c|}{ Range of Sample Sizes } & \multirow{2}{*}{$\begin{array}{l}\text { Cumulative } \\
\text { Sample Size }\end{array}$} & \multirow{2}{*}{$\begin{array}{c}\text { Average } \\
\text { Sample Size }\end{array}$} \\
\hline & & Lower & Upper & Difference & Significant & Non-Significant & Significant Rate & Lower & Upper & & \\
\hline AF-BI & 2 & 0.010 & 0.338 & 0.328 & 1 & 1 & $50.00 \%$ & 239 & 374 & 613 & 494 \\
\hline TE-ACC & 3 & 0.060 & 0.069 & 0.009 & 0 & 3 & $0.00 \%$ & 125 & 630 & 905 & 302 \\
\hline AI-BI & 5 & 0.021 & 0.190 & 0.169 & 4 & 1 & $80.00 \%$ & 184 & 700 & 1737 & 347 \\
\hline PE-BI & 9 & 0.152 & 0.359 & 0.207 & 9 & 0 & $100.00 \%$ & 14 & 400 & 2446 & 272 \\
\hline PU-ATT & 2 & 0.290 & 0.424 & 0.134 & 2 & 0 & $100.00 \%$ & 239 & 239 & 478 & 239 \\
\hline PEOU-ATT & 3 & 0.198 & 0.441 & 0.243 & 3 & 0 & $100.00 \%$ & 239 & 436 & 929 & 310 \\
\hline PU-BI & 13 & 0.094 & 0.625 & 0.531 & 11 & 2 & $84.62 \%$ & 30 & 700 & 3217 & 247 \\
\hline PEOU-BI & 10 & 0.047 & 3.113 & 3.066 & 7 & 3 & $70.00 \%$ & 30 & 530 & 1871 & 187 \\
\hline EE-BI & 10 & 0.000 & 0.530 & 0.530 & 9 & 1 & $90.00 \%$ & 14 & 400 & 2446 & 245 \\
\hline FC-BI & 9 & 0.009 & 0.250 & 0.241 & 6 & 3 & $66.67 \%$ & 33 & 574 & 2757 & 306 \\
\hline TP-BI & 3 & 0.067 & 0.135 & 0.068 & 3 & 0 & $100.00 \%$ & 239 & 700 & 1634 & 545 \\
\hline TR-BI & 7 & 0.011 & 0.302 & 0.291 & 3 & 4 & $42.86 \%$ & 30 & 254 & 720 & 103 \\
\hline SI-BI & 13 & 0.015 & 0.252 & 0.237 & 7 & 6 & $53.85 \%$ & 30 & 646 & 2700 & 208 \\
\hline SN-BI & 5 & 0.120 & 0.309 & 0.189 & 5 & 0 & $100.00 \%$ & 239 & 700 & 2097 & 419 \\
\hline
\end{tabular}

Note: AF-affordability; TE—technology experience; AI—anxiety; PE—performance expectancy; PU—perceived usefulness; PEOU—perceived ease of use; EE-effort expectancy; FC—facilitating conditions; TP—technical performance; TR—-trust; SI—social influence; SN—subjective norm; ATT—attitude; BI—behavioral intention; ACC—acceptance. 


\subsection{Heterogeneity Test}

Heterogeneity test is an important part of meta-analysis. It tests whether the included data is heterogeneous. Only homogeneous data can be combined for statistical analysis, such as merging or comparison, and the analysis is to eliminate the causes of heterogeneity as much as possible. It is necessary to select an appropriate statistical model based on the results. The more widely used heterogeneity test is the $Q$ test. If the $Q$ test results are significant $p \leq 0.05$, it indicates that there is heterogeneity between studies; otherwise, it indicates that multiple studies have homogeneity. When the effect value is heterogeneous in the process of heterogeneity detection. The heterogeneity analysis and judgment are performed first, and the extreme effect value is deleted. The fixed effect model is used to combine the effects when the $Q$ test result is not significant. However, when the effect of the $Q$ test is not obvious, and its statistics are near the critical value, two models are used for analysis to make the conclusion more reliable. The heterogeneity test of this study is shown in Table 5. According to the principle of heterogeneity treatment, random effect models were used for $\mathrm{H} 1$ and $\mathrm{H} 5$, and fixed effect model was used for the rest hypothesis in the effect combination of this study.

Table 5. Heterogeneity test and bias test.

\begin{tabular}{cccccccccc}
\hline \multirow{2}{*}{ Hypothesis } & $\begin{array}{c}\text { Pair-Wise } \\
\text { Relationship }\end{array}$ & $\mathbf{K}$ & $\mathbf{N}$ & \multicolumn{3}{c}{ Heterogeneity Test } & \multicolumn{2}{c}{ Egger Test } \\
\cline { 6 - 9 } & & & & Q Value & $p$ Value & $\mathbf{I}^{\mathbf{2}}$ & Tau Squared & Coef. & $\mathbf{p}$ \\
\hline H1 & AF-BI & 2 & 916 & 0.000 & - & - & -0.256 & - \\
H2 & TE-ACC & 3 & 496 & 1.480 & 0.477 & $0.0 \%$ & 0.000 & -0.139 & 0.093 \\
H3 & AI-BI & 5 & 1737 & 8.660 & 0.070 & $54.0 \%$ & 0.006 & -0.079 & 0.736 \\
H4 & PU-ATT & 2 & 508 & 2.080 & 0.149 & $49.0 \%$ & 0.005 & -0.127 \\
H5 & PEOU-ATT & 3 & 944 & 12.110 & 0.002 & $83.5 \%$ & 0.015 & -0.003 & 0.283 \\
H6 & PU-BI & 13 & 2973 & 13.220 & 0.153 & $31.9 \%$ & 0.002 & 0.279 & 0.432 \\
H7 & PEOU-BI & 10 & 1871 & 9.010 & 0.061 & $55.6 \%$ & 0.006 & 0.078 & 0.477 \\
H8 & PE-BI & 9 & 2692 & 14.790 & 0.063 & $45.9 \%$ & 0.003 & 0.309 & 0.773 \\
H9 & EE-BI & 10 & 3266 & 8.500 & 0.203 & $29.5 \%$ & 0.002 & 0.193 & 0.950 \\
H10 & TR-BI & 7 & 1333 & 11.600 & 0.072 & $48.3 \%$ & 0.005 & 0.166 & 0.747 \\
H11 & TP-BI & 3 & 1279 & 1.800 & 0.407 & $0.0 \%$ & 0.000 & 0.043 & 0.154 \\
H12 & FC-BI & 9 & 3370 & 7.330 & 0.120 & $45.4 \%$ & 0.002 & 0.238 & 0.253 \\
H13 & SI-BI & 13 & 1942 & 15.920 & 0.069 & $43.5 \%$ & 0.004 & 0.293 & 0.014 \\
H14 & SN-BI & 5 & 2112 & 6.190 & 0.185 & $35.4 \%$ & 0.002 & 0.176 & 0.875 \\
\hline
\end{tabular}

Note: $\mathrm{K}$ is the sample of the independent study; $\mathrm{N}$ is the total sample size of the $\mathrm{K}$ studies; $\mathrm{I}^{2}$ represents the true difference of the effect value as a percentage of the total observed variation; Tau Squared represents the percentage of variation between studies that can be used to calculate weights; “- "Indicates missing values; the $p$ value in the Egger test is a significance test value for publication bias. If $p<0.05$, there is a publication bias.

\subsection{Meta-Analysis of Influencing Systematic Attributes}

The meta-analysis results of the influencing systematic attributes of gerontechnology adoption are shown in Table 6. The combined effect value $r$ reflects the correlation between the various assumptions. From the data in Table 3, Affordability $(r=-0.010, p=0.973>0.05)$ has no significant effect on BI. Technology experience $(r=-0.046, p=0.093>0.05)$ has no significant effect on the usage acceptance. Anxiety $(r=-0.117, p<0.001)$ has a significant negative correlation to BI. In addition, PU $(r=0.339$, $p<0.001)$ and PEOU $(r=0.316, p<0.001)$ have a significant positive correlation with ATT, where the effect of PU on ATT is greater than that of PEOU on ATT. PE $(r=0.292, p<0.001)$, PU $(r=0.275$, $p<0.001)$, EE $(r=0.189, p<0.001)$, PEOU $(r=0.184, p<0.001)$, TEC Performance $(r=0.077, p<0.001)$, Trust $(r=0.147, p<0.001)$, SN $(r=0.208, p<0.001)$ has a significant positive correlation for BI. The significant impact of these influencing systematic attributes on $\mathrm{BI}$ is ranked as $\mathrm{PE}>\mathrm{PU}>\mathrm{EE}>$ PEOU $>$ TR $>$ TF. At the same time, SI $(r=0.116, p=0.001)$ and FC $(r=0.046,0.001<p<0.05)$ have a positive correlation with BI. Therefore, the hypothesis that H3, H4, H5, H6, H7, H8, H9, H10, H11, H12, H13, H14 hypotheses have been verified; $\mathrm{H} 1$ and $\mathrm{H} 2$ have not been verified. 
Table 6. Meta-analysis.

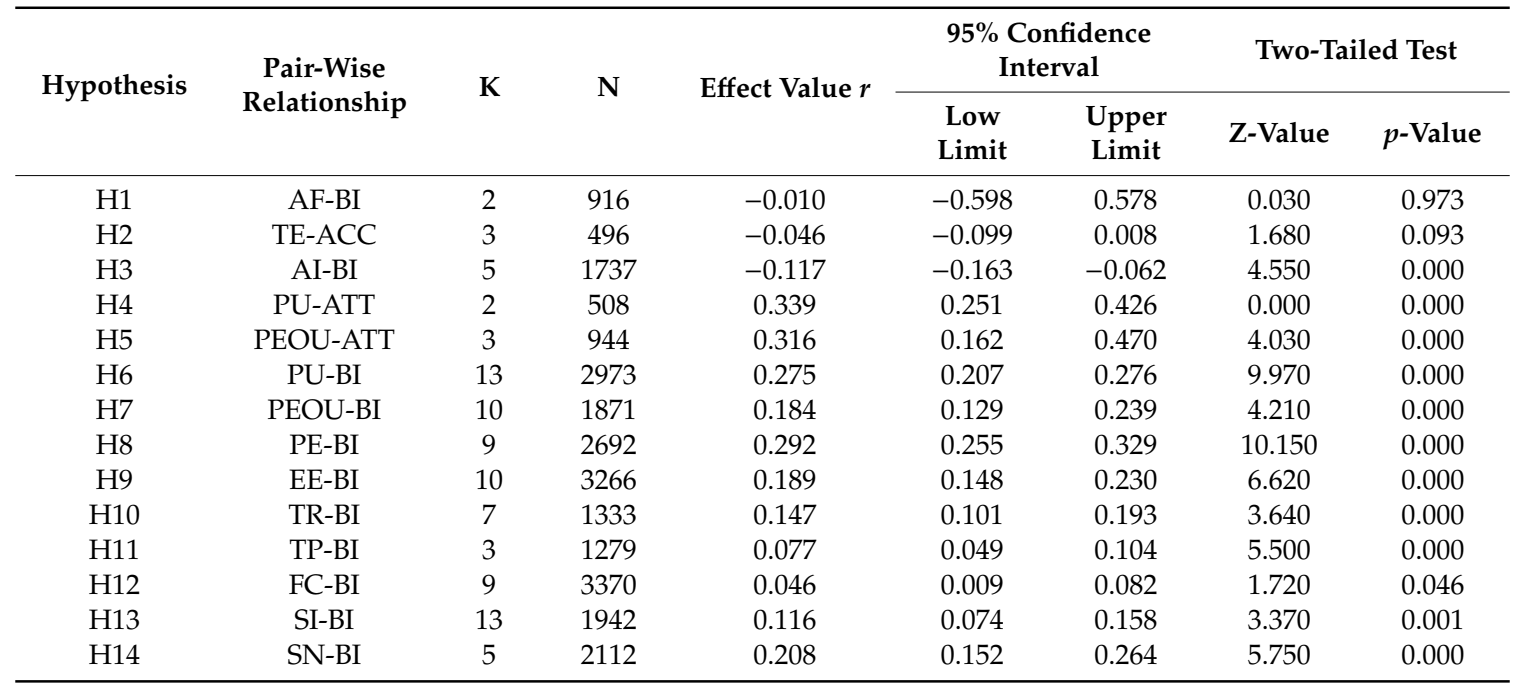

Note: The $p$-value is the significance test value of the combined effect value, $p<0.001$ indicates a significant correlation, and $p<0.05$ indicates a correlation.

\subsection{Bias Test}

Although meta-analysis has many advantages, its biggest limitation lies in the reanalysis process based on the existing study results, so the quality is affected by the quality of the date from the sample studies. In particular, the meta-analysis should collect the relevant literature as comprehensively as possible to reduce publication bias, due to the existence of bias. In general, the Egger test is used to identify and control publication deviations. The principle is to analyze whether the publication bias exists through the significant difference between the Coef regression intercept term and 0. The Egger test was performed on each hypothesis, since the study involved multiple variable relationships, presented in Table 5. A test value $\mathrm{p}>0.05$ indicates that the intercept term is not significantly different from 0, according to Egger's test principle. Assume that $\mathrm{H} 1$ and $\mathrm{H} 4$ cannot complete the detection, due to the small number of documents. In addition to this, the data indicate that there are no publication bias issues for other hypothetical relationships except Hypothesis H13. When there are biases, there are two main causes publication bias and file-drawer problem. Publication bias refers to the significance of study results that are "statistically significant" $(p<0.05)$ compared to non-significant studies that are "not statistically significant" ( $p>0.05$ ) [39]. The file-drawer problem is a tendency of the author and its funding unit to be unwilling to provide insignificant results or invalid results [40].

\section{Discussions}

A meta-analysis method was used to comprehensively analyze and evaluate the effects of 12 influencing systematic attributes from 25 results on the attitudes and behavioral intentions of gerontechnology adoption. The analysis results show that PU (perceived usefulness) and PEOU (perceived ease of use) have a significant positive correlation with ATT (attitude). PE (performance expectancy), PU (perceived usefulness), EE (effort expectancy), PEOU (perceived ease of use), TP (technical performance), SN (subjective norm) have a significant positive correlation for BI. FC (facilitating conditions) and SI (social influence) present a correlation to BI (behavioral intention). AI (anxiety) has a significant negative impact on the behavior intention. The results of the study indicate that user adoption is affected by many systematic attributes. In addition, this study also proves the importance of technology adoption models, such as TAM, UTAUT on gerontechnology. Based on the results of the study, an overall framework of influencing systematic attributes for gerontechnology adoption is proposed. (Figure 4) 


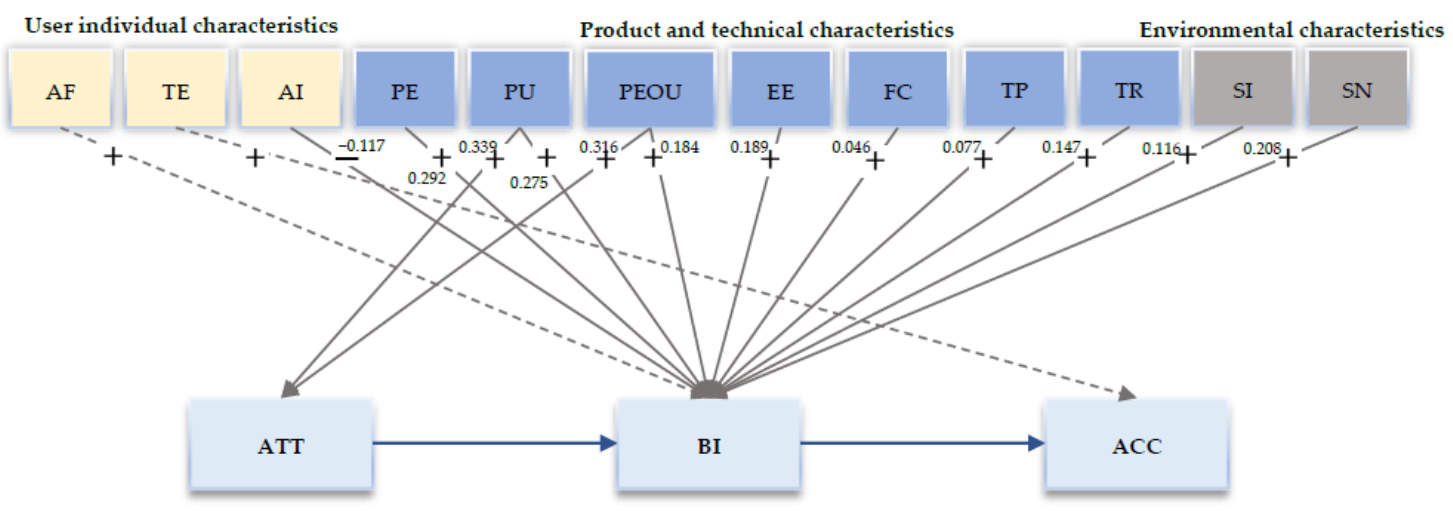

Figure 4. Gerontechnology adoption framework.

Note: (1) AF-affordability; TE-technology experience; AI-anxiety; PE-performance expectancy; PU—perceived usefulness; PEOU—perceived ease of use; EE-effort expectancy; FC—facilitating conditions; TP—technical performance; TR—-trust; SI—social influence; $\mathrm{SN}$-subjective norm; ATT—attitude; BI-behavioral intention; ACC—acceptance. (2) The number in the figure is effect value $r$. (3) The dashed line means that the pairwise relationship is not significant.

The influencing systematic attributes presented in the study results come from different theories, but their meanings are also partially the same. Although it is not possible to combine them completely in the meta-analysis. However, in order to help marketing agencies to understand the influencing attributes of gerontechnology adoption, and to better promote the implementation of gerontechnology adoption. This study attempts to interpret the analysis results from the three dimensions of human, machine and environment based on ergonomics. Gerontechnology originates from ergonomics, which is mainly composed of the elderly, the technology itself, and the surrounding environment of the elderly [1].

In terms of individual user characteristics, anxiety (H3) has a significant negative impact on BI, which indicates that in the future, it is necessary to pay attention to how to reduce the anxiety of technology for elderly users in the process of adoption, while improving the user experience, and creating a relaxed and joyful atmosphere during use [22]. In terms of technical product characteristics, PE and PU showed a strong positive correlation on BI. It shows that elderly users attach great importance to the benefits expected from the use of technology products. Therefore, when developing and designing gerontechnology products and services, it is important to consider whether the products and services can meet the following needs of seniors: Social interaction (enhancing communication with friends and reducing loneliness) [27]; health care (helps understand and improve personal health and access to more health resources) [26]. In addition, EE $(r=0.189)$ and PEOU $(r=0.184)$ have significant effects on BI. Relevant personnel are reminded that when designing technical products for the elderly, it is particularly necessary to consider reducing the difficulty of system operation of the product [24]. As well as the time and economic costs required during use (reducing the time of diagnosis and treatment, reducing medical costs) [26]. For example, through the product, the seniors can easily interact with others and doctors anytime, anywhere. In terms of social and environmental characteristics, SN has a significant positive correlation with BI, and SI shows a positive correlation with BI. It shows that the elderly are affected by the gradual degradation of physiological functions and aging. Compared with young people, the elderly are more likely to be affected by social environments, such as family, friends, and institutions, especially the recommendations of important friends and the surrounding environment $[24,35]$.

This study is summarized the following references for the R\&D Worker and the marketing managers to promote the adoption of gerontechnology:

1. Relevant institutions should provide gerontechnology services and product designs that address the real needs of the seniors, and have an in-depth understanding of the elderly's needs for 
health, life support, and social issues. For example, design a smart home with the function of identifying and analyzing the daily activity information to proactively assist the seniors in their daily lives [41].

2. In the design process of gerontechnology products, attention needs to be paid to reducing the system operation difficulty of the product, the time and economic costs required during use, thereby reducing the technical anxiety, improving the user experience, and creating a relaxed and pleasant atmosphere during use.

3. In addition, in the promotion process of technology products, it is necessary to consider that the seniors are more susceptible to social environmental influences from family members, friends, and institutions than young people. Marketers should pay attention to their friends and the surrounding environmental attributes to start the promotion.

\section{Conclusions}

Mete-analysis was used to quantitatively analyze the influencing attributes of the gerontechnology adoption in the world in the past ten years, and based on Prior studies, a framework of attributes affecting the gerontechnology adoption was proposed. The contribution of this study lies in the use of scientific theories and methods, summarizing the current systematic attributes influencing the adoption of gerontechnology, enriching the literature on gerontechnology adoption. The results enable future studies or related institutions to have a clearer understanding of the needs of the seniors and their awareness of gerontechnology. The intensity of the effect value of each influencing factor obtained by this study can provide a more accurate direction for the future innovation and promotion of gerontechnology, and make a clearer plan for future study in the field of gerontechnology.

This study excludes some unexpected data that cannot be entered into the meta-analysis. There are deviations, due to incomplete data. Future study needs to include the various database in the field and use the concept of unified academic meaning to conduct a study to obtain broader study significance. The systematic attributes appeared less in prior studies and meta-analysis was unable to analyze them, so they were not included in this study, such as risk, security, privacy and other attributes. The influence of these attributes on the adoption of technology is also important, but there are few relevant empirical studies at this stage. In addition, the effect of era background and limitations are important for the users 'cognition of technology [42]. However, few studies have been conducted on this issue. Future study needs to investigate these influencing attributes to have a more comprehensive understanding of the gerontechnology adoption. This study only intercepted the empirical study results of the past ten years for extraction analysis, due to the rapid progress of assistive technology and information technology [43].

Author Contributions: All authors contributed to the paper. Conceptualization, J.Z.; formal analysis, B.Z.; data curation, Y.Z.; funding acquisition, R.T.; writing-original draft, J.Z.; writing-review and editing, M.-L.T. All authors have read and agreed to the published version of the manuscript.

Funding: This research was funded by National Natural Science Foundation of China, grant number 51675159.

Conflicts of Interest: The authors declare no conflict of interest.

\section{References}

1. Kwon, S. (Ed.) Gerontechnology: Research, Practice, and Principles in the Field of Technology and Aging; Springer Publishing Company: New York, NY, USA, 2017.

2. Piau, A.; Campo, E.; Rumeau, P.; Vellas, B.; Nourhashemi, F. Aging society and gerontechnology: A solution for an independent living? J. Nutr. Health Aging 2014, 18, 97-112. [CrossRef] [PubMed]

3. Eli Carmeli, P.T. Aspects of assistive gerontechnology. J. Endocr. Genet. 2009, 8, 215-218. [CrossRef]

4. Fozard, J.L.; Rietsema, J.; Bouma, H.; Graafmans, J.A.M. Gerontechnology: Creating enabling environments for the challenges and opportunities of aging. Educ. Gerontol. 2000, 26, 331-344. 
5. Petermans, J.; Piau, A. Gerontechnology: Don't miss the train, but which is the right carriage? Eur. Geriatr. Med. 2017, 8, 281-283. [CrossRef]

6. Fernández-Caballero, A.; González, P.; Navarro, E.; Cook, D. Special Issue — Pervasive Computing for Gerontechnology. Pervasive Mob. Comput. 2017, 34, 1-2. [CrossRef]

7. Sixsmith, A.; Sixsmith, J. Smart care technologies: Meeting whose needs? J. Telemed. Telecare 2000, 6, 190-192. [CrossRef]

8. Ma, Q.; Chan, A.H.S.; Chen, K. Personal and other factors affecting acceptance of smartphone technology by older Chinese adults. Appl. Ergon. 2016, 54, 62-71. [CrossRef]

9. Koceski, S.; Koceska, N. Evaluation of an Assistive Telepresence Robot for Elderly Healthcare. J. Med. Syst. 2016, 40, 1-7. [CrossRef]

10. Puri, A.; Kim, B.; Nguyen, O.; Stolee, P.; Tung, J.; Lee, J. User Acceptance of Wrist-Worn Activity Trackers Among Community-Dwelling Older Adults: Mixed Method Study. JMIR mHealth uHealth 2017, 5, e173. [CrossRef]

11. Rosenthal, R.; DiMatteo, M.R. Meta-Analysis: Recent Developments in Quantitative Methods for Literature Reviews. Annu. Rev. Psychol 2001, 52, 59-82. [CrossRef]

12. GLASS, G. V Primary, Secondary, and Meta-Analysis of Research. Educ. Res. 1976, 5, 3-8. [CrossRef]

13. Da Silva, L.M.; Bitencourt, C.C.; Faccin, K.; Iakovleva, T. The role of stakeholders in the context of responsible innovation: A meta-synthesis. Sustainability 2019, 11, 1766. [CrossRef]

14. Zhao, Y.; Ni, Q.; Zhou, R. What factors influence the mobile health service adoption? A meta-analysis and the moderating role of age. Int. J. Inf. Manag. 2018, 43, 342-350. [CrossRef]

15. Hauk, N.; Hüffmeier, J.; Krumm, S. Ready to be a Silver Surfer? A Meta-analysis on the Relationship Between Chronological Age and Technology Acceptance. Comput. Hum. Behav. 2018, 84, 304-319. [CrossRef]

16. Wilson, J.R. Fundamentals of ergonomics in theory and practice. Appl. Ergon. 2000, 31, 557-567. [CrossRef]

17. Pal, D.; Funilkul, S.; Vanijja, V.; Papasratorn, B. Analyzing the Elderly Users' Adoption of Smart-Home Services. IEEE Access 2018, 6, 51238-51252. [CrossRef]

18. Wang, K.H.; Chen, G.; Chen, H.G. A model of technology adoption by older adults. Soc. Behav. Pers. 2017, 45, 563-572. [CrossRef]

19. Cimperman, M.; Makovec Brenčič, M.; Trkman, P. Analyzing older users' home telehealth services acceptance behavior-applying an Extended UTAUT model. Int. J. Med. Inform. 2016, 90, 22-31. [CrossRef]

20. Pal, D.; Triyason, T.; Funilkul, S.; Chutimaskul, W. Smart Homes and Quality of Life for the Elderly: Perspective of Competing Models. IEEE Access 2018, 6, 8109-8122. [CrossRef]

21. Pan, S.; Jordan-Marsh, M. Internet use intention and adoption among Chinese older adults: From the expanded technology acceptance model perspective. Comput. Hum. Behav. 2010, 26, 1111-1119. [CrossRef]

22. Hoque, R.; Sorwar, G. Understanding factors influencing the adoption of mHealth by the elderly: An extension of the UTAUT model. Int. J. Med. Inform. 2017, 101, 75-84. [CrossRef] [PubMed]

23. Mitzner, T.L.; Savla, J.; Boot, W.R.; Sharit, J.; Charness, N.; Czaja, S.J.; Rogers, W.A. Technology Adoption by Older Adults: Findings from the PRISM Trial. Gerontologist 2019, 59, 34-44. [CrossRef] [PubMed]

24. Syed-Abdul, S.; Malwade, S.; Nursetyo, A.A.; Sood, M.; Bhatia, M.; Barsasella, D.; Liu, M.F.; Chang, C.C.; Srinivasan, K.; Raja, R.; et al. Virtual reality among the elderly: A usefulness and acceptance study from Taiwan. BMC Geriatr. 2019, 19, e223. [CrossRef]

25. Quaosar, G.M.A.A.; Hoque, M.R.; Bao, Y. Investigating factors affecting elderly's intention to use m-health services: An empirical study. Telemed. e-Health 2018, 24, 309-314. [CrossRef] [PubMed]

26. Zhou, M.; Zhao, L.; Kong, N.; Campy, K.S.; Qu, S.; Wang, S. Factors influencing behavior intentions to telehealth by Chinese elderly: An extended TAM model. Int. J. Med. Inform. 2019, 126, 118-127. [CrossRef] [PubMed]

27. Ramírez-Correa, P.; Grandón, E.E.; Ramírez-Santana, M.; Órdenes, L.B. Explaining the use of social network sites as seen by older adults: The enjoyment component of a hedonic information system. Int. J. Environ. Res. Public Health 2019, 16, 1673. [CrossRef] [PubMed]

28. Chu, L.; Chen, H.W.; Cheng, P.Y.; Ho, P.; Weng, I.T.; Yang, P.L.; Chien, S.E.; Tu, Y.C.; Yang, C.C.; Wang, T.M.; et al. Identifying features that enhance older adults' acceptance of robots: A mixed methods study. Gerontology 2019, 65, 441-450. [CrossRef] [PubMed]

29. Li, J.; Ma, Q.; Chan, A.H.; Man, S.S. Health monitoring through wearable technologies for older adults: Smart wearables acceptance model. Appl. Ergon. 2019, 75, 162-169. [CrossRef] 
30. Talukder, M.S.; Sorwar, G.; Bao, Y.; Ahmed, J.U.; Palash, M.A.S. Predicting antecedents of wearable healthcare technology acceptance by elderly: A combined SEM-Neural Network approach. Technol. Forecast. Soc. Chang. 2020, 150, e119793. [CrossRef]

31. Pai, J.C.; Tu, F.M. The acceptance and use of customer relationship management (CRM) systems: An empirical study of distribution service industry in Taiwan. Expert Syst. Appl. 2011, 38, 579-584. [CrossRef]

32. Kim, E.H.; Gellis, Z.D.; Bradway, C.K.; Kenaley, B. Depression care services and telehealth technology use for homebound elderly in the United States. Aging Ment. Health 2019, 23, 1164-1173. [CrossRef] [PubMed]

33. Fishbein, M.; Ajzen, I. Belief, Attitude, Intention, and Behavior: An Introduction to Theory and Research; Addison-Wesley: Boston, MA, USA, 1975.

34. Ajzen, I. The theory of planned behavior. Organ. Behav. Hum. Decis. Process. 1991, 50, 179-211. [CrossRef]

35. Chen, M.; Lu, T.; Chen, K.; Liu, C.E. A TAM-based study on senior citizens digital learning and user behavioral intention toward use of broadband network technology services provided via television. Afr. J. Bus. Manag. 2011, 5, 7099-7110.

36. Cajita, M.I.; Hodgson, N.A.; Budhathoki, C.; Han, H.R. Intention to Use mHealth in Older Adults with Heart Failure. J. Cardiovasc. Nurs. 2017, 32, E1-E7. [CrossRef]

37. Chen, C. Science Mapping: A Systematic Review of the Literature. J. Date. Inform. Sci. 2017, 2, 1-40. [CrossRef]

38. Egger, M.; Smith, G.D.; Phillips, A.N. Meta-analysis: Principles and procedures. Brit. Med. J. 1997, 315, 1533-1537. [CrossRef] [PubMed]

39. Dickersin, K. The existence of publication bias and risk factors for its occurrence. JAMA, J. Am. Med. Assoc. 1990, 263, 1385-1389. [CrossRef]

40. Rosenthal, R. The file drawer problem and tolerance for null results. Psychol. Bull. 1979, 86, 638-641. [CrossRef]

41. Liu, Y.; Ouyang, D.; Liu, Y.; Chen, R. A novel approach based on time cluster for activity recognition of daily living in smart homes. Symmetry 2017, 9, 212. [CrossRef]

42. Huang, T.; Liu, H. Acceptability of robots to assist the elderly by future designers: A case of Guangdong Ocean University industrial design students. Sustainability 2019, 11, 4139. [CrossRef]

43. Yeh, L.T.; Tseng, M.L.; Lim, M. Assessing the carry-over effects of both human capital and organizational forgetting on sustainability performance using dynamic data envelopment analysis. J. Clean. Prod. 2020, 250, 119584. [CrossRef]

(C) 2020 by the authors. Licensee MDPI, Basel, Switzerland. This article is an open access article distributed under the terms and conditions of the Creative Commons Attribution (CC BY) license (http://creativecommons.org/licenses/by/4.0/). 